\title{
Appendage of the Uterus
}

National Cancer Institute

\section{Source}

National Cancer Institute. Appendage of the Uterus. NCI Thesaurus. Code C12321.

The accessory structures of the uterus, including the ovaries, fallopian tubes, broad ligament, and the ovarian and uterine ligaments. 